\title{
The incidence of ringed fibres and sarcoplasmic masses in normal and diseased muscle
}

\author{
JAAP BETHLEM AND GEORGE K. VAN WIJNGAARDEN \\ From the Neurological Clinic, Wilhelmina Gasthuis, University of Amsterdam, the Netherlands
}

Cross-striated myofibrils may take aberrant courses within the sarcolemmal tube of the muscle fibre. They usually run a spiral course around the longitudinal axis of the muscle fibre and thus in cross-sections a ring of myofibrils is to be seen. Depending on the speed of the spiral this ring is more or less complete, but, of course, never forms a closed circle. The muscle fibre surrounded by a ring of myofibrils is called a ringed fibre. The aberrant myofibrils are called 'spiral annulets' and Ringbände or Ringbinden in the German literature.

The myofibrils occasionally run a more complicated course and may penetrate the muscle fibre, coming to the surface on the other side. In these cases cross-sections show a variety of formations, for instance, the figure eight. Even so the muscle fibre is called a ringed fibre.

A large quantity of sarcoplasm at the periphery of the myofibrils within the same sarcolemmal tube is called a sarcoplasmic mass. In this mass, large vesicular nuclei, often with a prominent nucleolus, are invariably present.

If these criteria are accepted, sarcoplasmic masses cannot be confused with artifacts of fixation. Infrequently central masses of sarcoplasm may be seen within the muscle fibre.

\section{RINGED FIBRES IN HUMAN MUSCLE}

The first description of ringed fibres in human muscle was given by Muenzer (1893), who observed them in the biceps of a patient suffering from muscular dystrophy, and in a muscle specimen from the dorsal aspect of the foot in a leg amputated for gonitis tuberculosa. In the same year, Schaffer described ringed fibres found in the calf muscle in the body of an executed criminal; he regarded these annular structures as artifacts. Hoen (1898) found ringed fibres in the normal human uvula. Martinotti (1901) observed them in the biceps in a case of acromegaly, and Steiner (1905) in the gastrocnemius in a case of dermatomyositis; Thulin (1908) found them in the normal uvula, and Bacaloglu and Scriban (1916) in muscular dystrophy.

In 1918, Heidenhain described ringed fibres in the muscles of patients with dystrophia myotonica. He is regarded by many authors as the first to have described these structures. Ringed fibres have since been described by Slauck (1921) in myxoedema; by Schütz (1923) in the external ocular muscles in six patients with exophthalmic goitre; by D'Antona (1926) in spinal muscular atrophy; by Scriban and Paulian (1932) in pseudohypertrophic myopathy.

Bucciante and Luria (1933) examined the rectus oculi superior in 75 necropsy cases, and always saw ringed fibres in this muscle in subjects over 32 years? 을 of age. Wohlfahrt and Wohlfart (1935) found ringec fibres in a case of muscular dystrophy and one of dystrophia myotonica, and in the transversus perinei profundus in a patient not suffering fron any myopathy. Wohlfart $(1937,1938)$ described the $\overrightarrow{0}$ occurrence of ringed fibres in the external ocular muscles in human subjects aged 20 years or over. Bergstrand (1938) found them in a case of muscular dystrophy, one of dystrophia myotonica, and one of atrophy of the peroneus muscle; he also observed them in the diaphragm of a normal executed criminal. Graf (1949) found ringed fibres in the normal human uvula; Cooper and Daniel (1949) in the external ocular muscles of elderly subjects; Stöhr (1949) in the normal oesophagus; Goerttler (1950) in the normal vocal muscle. Wohlfart (1951) described ringed fibres in 14 out of 25 muscle specimens from 18 patients with dystrophia myotonica; he emphasized that ringed fibres are particularly frequent in this disease.

Ringed fibres have recently been described in the external ocular muscles by Siliotti (1954) and Voss (1957); in neuromuscular diseases of unspecified diagnosis by Perry, Smith, and Wrenn (1956) and by Goldstein and Zent (1961), and in nonneuromuscular diseases by Günther (1952).

Gamstorp (1956) mentions the occurrence of ringed fibres in one muscle biopsy from a patient suffering from adynamia episodica hereditaria. Bethlem (1958) found ringed fibres in dystrophia 
myotonica, and Berthrong and Griffith (1961) found them in muscular dystrophy. In 14 muscle biopsies from patients with various neuromuscular affections, ringed fibres were described by Greenfield, Shy, Alvord, and Berg (1957), who on one occasion also found them in a normal temporalis.

\section{RINGED FIBRES IN ANIMALS}

Bataillon (1891) described ringed fibres in frog larvae; Thulin (1908) in frogs, Bufo aqua, and in chameleons; Doms (1915) in frogs; Marcus (1925) in cyclostomata; Schwarz (1925) in the ocular muscles in dogs and rabbits; Voss (1932) in the axolotl and Proteus anguineus.

In the tensor tympani in dogs, cats, and white rats, ringed fibres were seen by Malan (1934), who observed an increasing frequency with increasing age. Wohlfart (1937) found them in the external ocular muscles in horses, cattle, dogs, and cats, exclusively around the A-fibres. Mori (1953) saw ringed fibres in the external ocular muscles in cats and guinea-pigs. Weiss and James (1955) described ringed fibres in the muscles of amphibian larvae.

\section{EXPERIMENTALLY PRODUCED RINGED FIBRES}

Vecchi (1925) observed ringed fibres in the sternocleidomastoid muscle in rats six months after dissection of the origin and insertion of this muscle and subsequent suturing of the free ends. The experiments were corroborated by Wohlfart (direct communication to Bergstrand) and in rabbits by Morris (1959).

Goerttler (1935) punched a fragment from the vastus lateralis in a rabbit, implanting this into the same site after rotating it $90^{\circ}$; ringed fibres developed in the immediate vicinity of the implant. The author ascribes this to the occurrence of tangential forces influencing the muscle tissue, as a result of the change in the muscle fibre course.

\section{SARCOPLASMIC MASSES}

Bucciante and Luria (1933) and Wohlfart (1937) called attention to the sarcoplasmic richness of the normal external ocular muscles at increasing age. Although several authors (Steiner, 1905; Bacaloglu and Scriban, 1916; Scriban and Paulian, 1932) casually mentioned the sarcoplasmic richness of muscle fibres which also contained ringed fibres, Wohlfart (1951) was the first to describe sarcoplasmic masses in 12 muscle biopsies from patients with dystrophia myotonica. He regarded these sarcoplasmic masses as pathognomonic of this disease.
Gamstorp (1956) pointed out the combined occurrence of ringed fibres and sarcoplasmic masses in a muscle biopsy from an atypical case of adynamia episodica hereditaria. Greenfield et al. (1957) saw sarcoplasmic masses in three cases of dystrophia myotonica. In all these specimens, ringed fibres were also encountered. Sarcoplasmic masses without ringed fibres were found by these authors in a case of scleroderma.

The purpose of this study is to present a description of the incidence of ringed fibres and sarcoplasmic masses in the normal human muscle and in neuromuscular disease. At the same time, this paper reports on the results obtained by two new methods of experimental production of ringed fibres in the muscles of guinea-pigs.

\section{MATERIAL AND METHODS}

Two hundred consecutive muscle biopsy specimens, measuring $1 \times 1 \times 2 \mathrm{~cm}$., received in the neuropathological department during the period 1956-61, were fixed in $10 \%$ formalin and embedded in paraffin. Six longitudinal and six transverse sections were cut through each specimen, and the sections were stained with haematoxylin-eosin and Gomori's trichrome.

At necropsy on 10 patients who had had no neuromuscular disease and were in the age group 50-80, specimens were obtained from seven different muscles of which the origin and insertion were attached to bone, $v i z$., the sternocleidomastoideus, the fourth intercostalis, the rectus abdominis, the triceps, the biceps, the vastus lateralis, and the gastrocnemius, all on the left side.

At necropsy on 10 other patients of the same age group, who had had no neuromuscular disease, specimens were obtained from seven different muscles not extending from bone to bone, viz., the right rectus oculi superior, the uvula, the vocal, the tongue, the diaphragm, the levator ani, and the sphincter ani externus.

All muscles obtained after death were fixed in $10 \%$ formalin and embedded in paraffin. Three transverse sections were cut through each specimen and stained with Gomori's trichrome.

All muscle specimens mentioned above were examined for ringed fibres. No attempt was made at quantitative investigation. When one section through a given muscle included only one ringed fibre, this muscle was recorded as positive. The same procedure was followed with regard to sarcoplasmic masses.

In five grown male guinea-pigs, the tendon of the left quadriceps femoris was severed from the patella. The tendon and the distal part of the muscle were dissected free from adjacent parts as much as possible so that the muscle could readily contract. After six months the animals were sacrificed, after which the left and the right quadriceps femoris were fixed in $10 \%$ formalin and embedded in paraffin. At 10 different levels, transverse sections were cut through each muscle and stained with Gomori's trichrome.

In five other grown male guinea-pigs the left quadriceps femoris was transversely cut into two halves, after which 
TABLE I

INCIDENCE OF RINGED FIBRES AND SARCOPLASMIC MASSES IN 200 MUSCLE BIOPSIES

\begin{tabular}{|c|c|c|c|c|c|}
\hline No. & Age & Muscle & Ringed Fibres & $\begin{array}{l}\text { Sarcoplasmic } \\
\text { Masses }\end{array}$ & Diagnosis \\
\hline 1 & 58 & Tibialis ant. & + & + & Muscular dystrophy \\
\hline 2 & 35 & Quadriceps & + & + & Muscular dystrophy \\
\hline 3 & 39 & Quadriceps & + & + & Muscular dystrophy \\
\hline 4 & 18 & Quadriceps & + & + & Muscular dystrophy \\
\hline 5 & 15 & Gastrocnemius & + & + & Muscular dystrophy \\
\hline 6 & 21 & Quadriceps & + & + & Muscular dystrophy \\
\hline 7 & 18 & Gastrocnemius & + & + & Muscular dystrophy \\
\hline 8 & 16 & Quadriceps & + & + & Muscular dystrophy \\
\hline 9 & 8 & Deltoid & + & + & Muscular dystrophy \\
\hline 10 & 47 & Quadriceps & + & + & Muscular dystrophy \\
\hline 11 & 38 & Quadriceps & + & + & Muscular dystrophy \\
\hline 12 & 56 & Quadriceps & + & + & Muscular dystrophy \\
\hline 13 & 62 & Biceps & + & - & Muscular dystrophy \\
\hline 14 & 49 & Tibialis ant. & + & + & Dystrophia myotonica \\
\hline 15 & 41 & Tibialis ant. & + & + & Dystrophia myotonica \\
\hline 16 & 50 & Tibialis ant. & + & + & Dystrophia myotonica \\
\hline 17 & 41 & Tibialis ant. & + & - & Dystrophia myotonica \\
\hline 18 & 52 & Trapezius & + & - & Dystrophia myotonica \\
\hline 19 & 16 & Gastrocnemius & + & - & Neurogenic disorder \\
\hline 20 & 66 & Peroneus & + & + & Neurogenic disorder \\
\hline 21 & 70 & Peroneus & + & + & Neurogenic disorder \\
\hline 22 & 16 & Gastrocnemius & + & + & Neurogenic disorder \\
\hline 23 & 46 & Peroneus & + & + & Myasthenia gravis \\
\hline 24 & 28 & Quadriceps & + & - & Periarteritis nodosa \\
\hline 25 & 73 & Gastrocnemius & + & - & Periarteritis nodosa \\
\hline 26 & 60 & Quadriceps & + & - & Sarcoidosis \\
\hline 27 & 38 & Sternohyoideus & 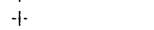 & - & Non-neuromuscular \\
\hline 28 & 68 & Quadriceps & + & - & Non-neuromuscular \\
\hline 29 & 66 & Quadriceps & + & + & Non-neuromuscular \\
\hline 30 & 37 & Quadriceps & + & + & Non-neuromuscular \\
\hline 31 & 61 & Gastrocnemius & + & - & Non-neuromuscular \\
\hline
\end{tabular}

a slice of about $4 \mathrm{~mm}$. thickness was cut from the proximal cut surface to ensure adequate separation of the two cut surfaces. One of the animals died after two and a half months and was not included in the investigation. The remaining four animals were sacrificed after six months. The left and the right quadriceps were processed as described.

\section{RESULTS}

BIOPSY CASES The 200 muscle biopsies included 31 specimens in which ringed fibres (Figs. 1 and 2) were found. Ringed fibres were especially seen in myogenic diseases, i.e., in 13 of the total of 46 cases of muscular dystrophy in this group and in five of the seven cases of dystrophia myotonica. They were found in only four of our 20 cases of muscular atrophy due to an affection of the lower motor neuron.

Of the 31 muscle biopsies in which ringed fibres were found, 21 also proved to contain sarcoplasmic masses (Table I). Aberrant myofibrils were often observed in the sarcoplasmic masses. Peripheral sarcoplasmic masses (Figs. 3 and 4) were much more frequent than central sarcoplasmic masses.

Case 24 was a 28-year-old woman with periarteritis nodosa. The quadriceps in this patient showed the typical changes of periarteritis nodosa; there were no ringed fibres. Eight weeks later a second biopsy specimen was obtained from a site immediately adjacent to the previous biopsy site. In the peripheral region of this second biopsy, bordering on the first, ringed fibres were observed.

NECROPSY CASES In the patients without neuromuscular disease, the muscles not extending from bone to bone contained considerably more ringed fibres and sarcoplasmic masses than those of which insertion and origin were attached to bone (Tables II and III).

EXPERIMENTAL CASES Ringed fibres were found in the quadriceps muscles of all five guinea-pigs in which the tendon of this muscle had been severed from the patella (Fig. 5). They were not found in the quadriceps femoris on the untreated side in these five animals.

Very many ringed fibres were also observed in the quadriceps femoris muscles of the four guinea-pigs in which this muscle had been halved; they were not found in the quadriceps on the untreated side. In both experimental groups there were no sarcoplasmic masses.

\section{COMMENT}

Our investigations have shown that in neuromuscular diseases ringed fibres often occur, but not always, in 


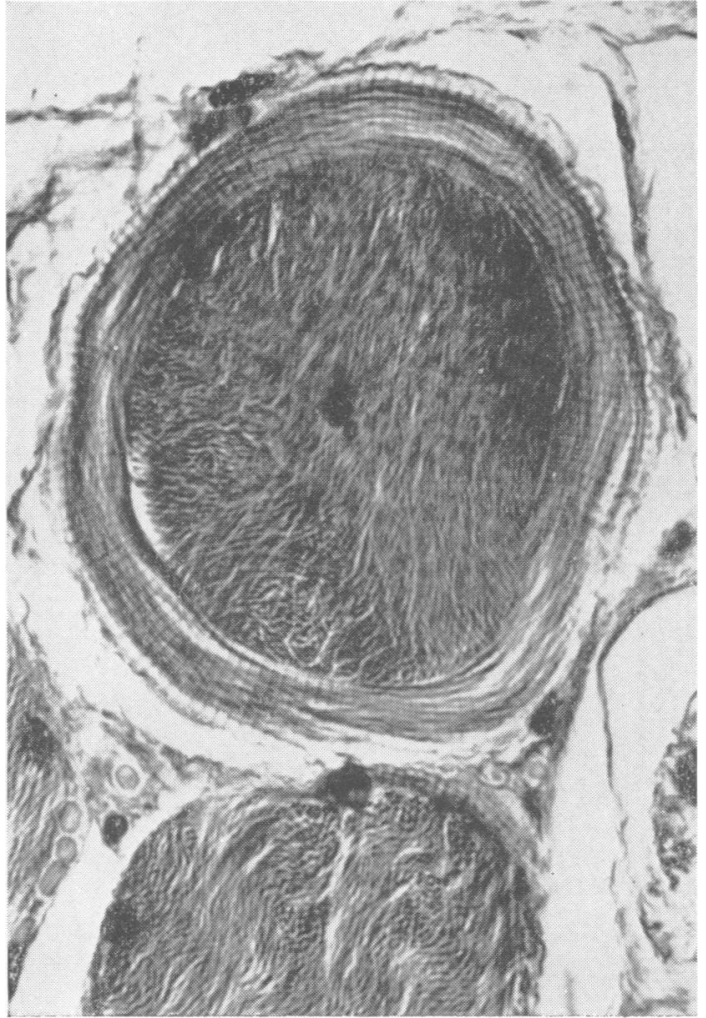

FIG. 1. Ringed fibre in transverse section. muscles in which sarcoplasmic masses are also found. Ringed fibres are frequently observed in muscle fibres which are also surrounded by a peripheral sarcoplasmic mass. In normal muscle, too, the combination of sarcoplasmic masses and ringed fibres is often encountered. Consequently there would seem to be a positive correlation between these two histological findings. It is possible that ringed fibres and sarcoplasmic masses are manifestations of the same mode of reaction of the muscle.

Ringed fibres were known to occur in normal human subjects in the ocular muscles, the uvula, the oesophagus, the vocalis, the diaphragm, the temporalis and the transversus perinei profundus. In patients not suffering from neuromuscular disease, we have found ringed fibres in many other muscles also. A fact of practical importance is the frequent presence of ringed fibres in the gastrocnemius, a muscle which readily lends itself to biopsy.

Vecchi (1925) observed the development of ringed fibres after dissection of the origin and the insertion of the muscle followed by suturing of the ends. In our experiments on guinea-pigs we were able to produce ringed fibres by detaching only the insertion or by interrupting the normal muscle course in that a fragment was removed half way the length of the muscle.

In our opinion, normal muscles form aberrant myofibrils in the form of ringed fibres when the

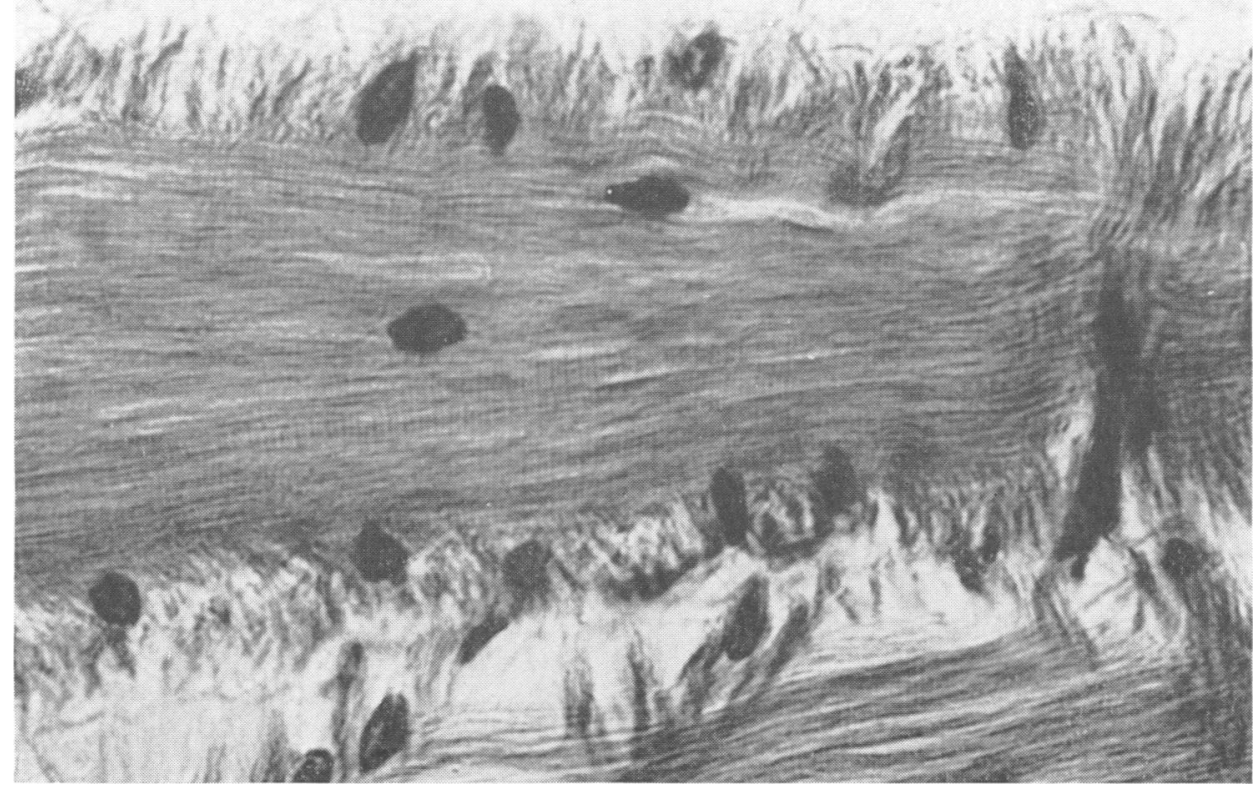

FIG. 2. Ringed fibre in longitudinal section. Note nuclei running parallel to aberrant myofibrils. 


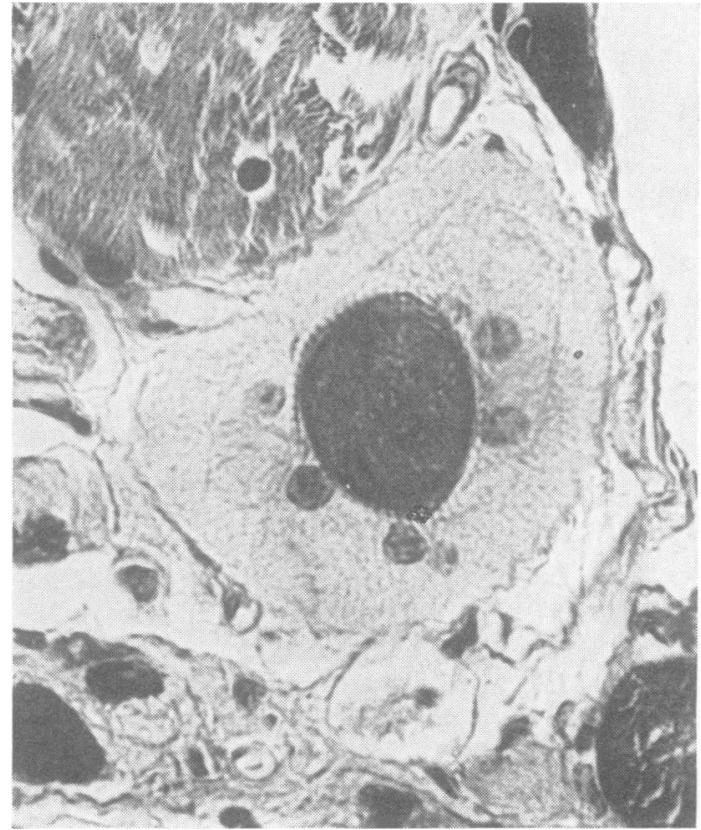

FIG. 3. Transverse section of sarcoplasmic mass with large vesicular nuclei, peripheral to a ringed fibre.

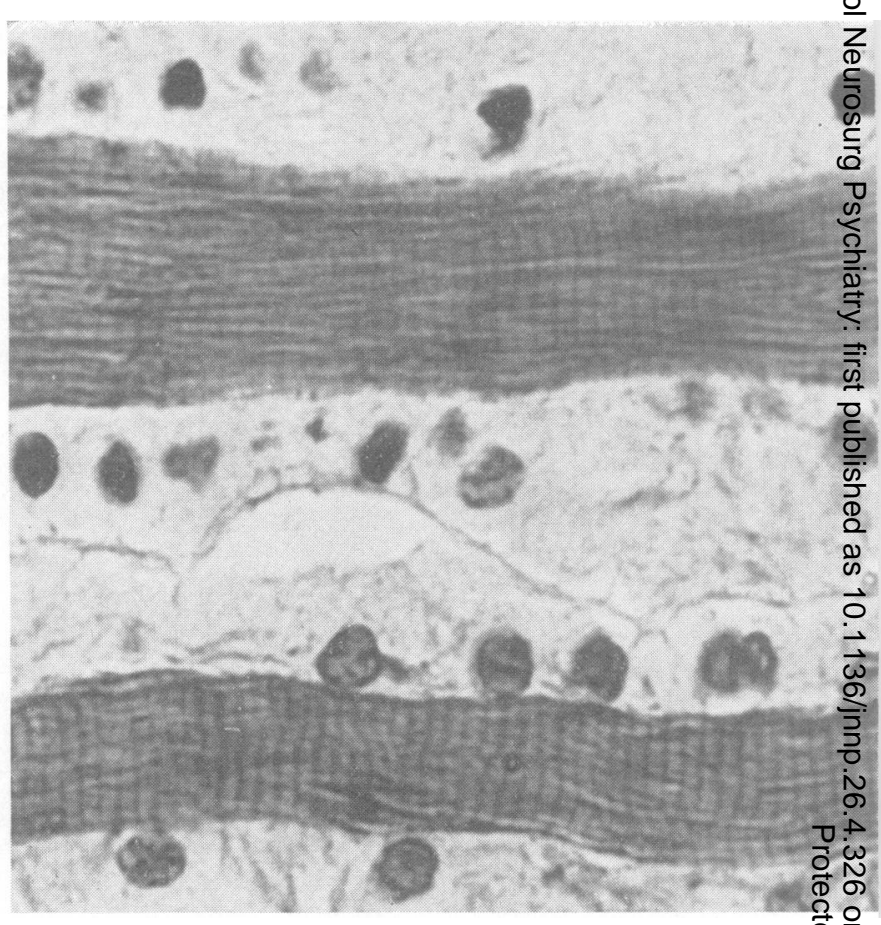

FIG. 4. Longitudinal section of peripheral sarcoplasmic masses尺ి

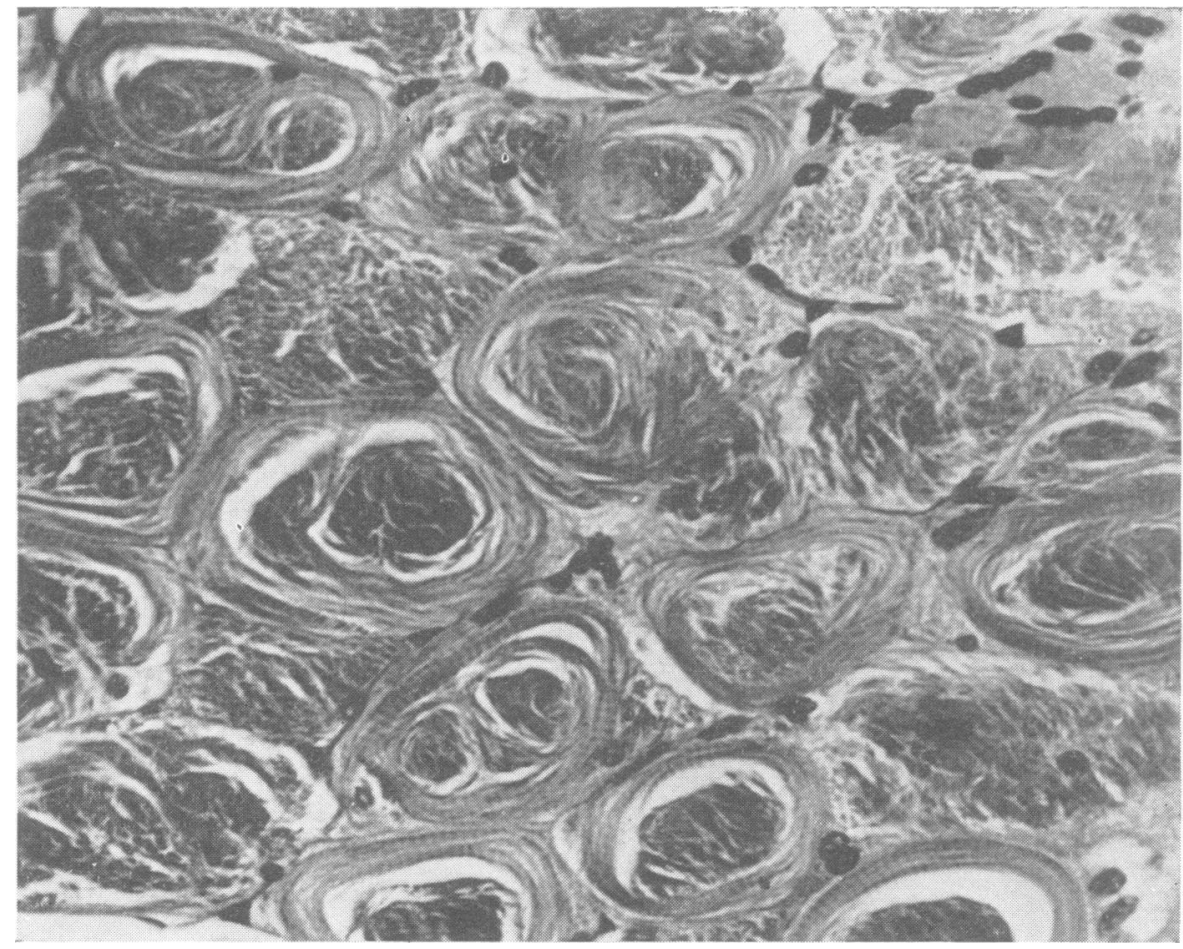

FIG. 5. Experimentally produced ringed fibres in the quadriceps femoris muscle of guineapig, in which the tendon of the muscle had been severed from the patella. 
TABLE II

INCIDENCE OF RINGED FIBRES AND SARCOPLASMIC MASSES IN MUSCLES NOT EXTENDING FROM BONE TO BONE IN 10 NECROPSY CASES

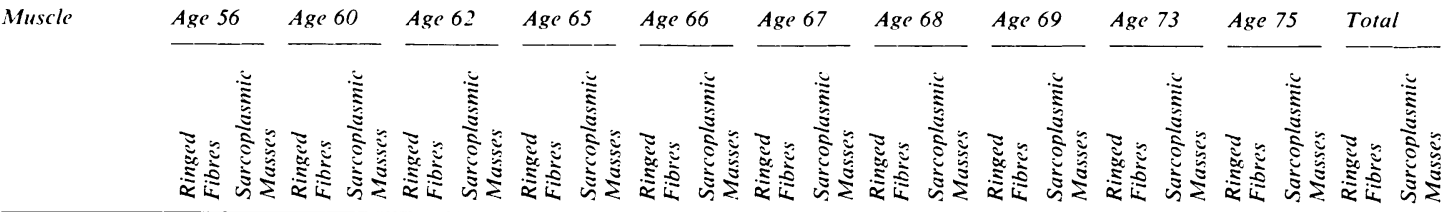

Rectus sup. oculi

Uvula

Vocalis

Tongue

Diaphragm

Levator ani

Sphincterani.ext.

TABLE III

INCIDENCE OF RINGED FIBRES AND SARCOPLASMIC MASSES IN MUSCLES WITH INSERTION AND ORIGIN ATTACHED TO BONE IN 10 NECROPSY CASES

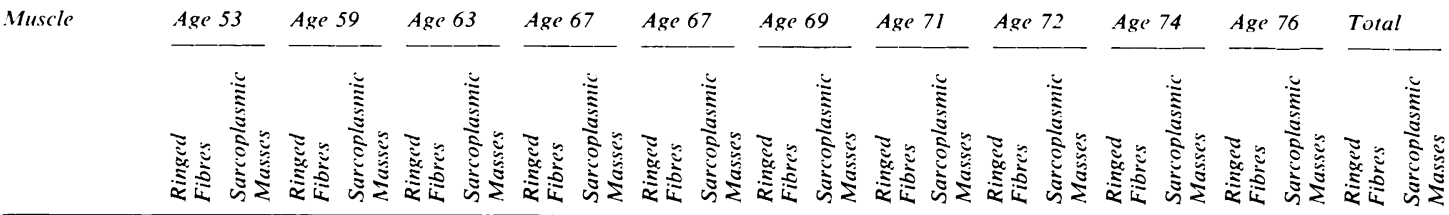

\footnotetext{
Sternocleidomastoid

Fourth external intercostalis

Rectus

abdominis

Biceps

Triceps

Vastus lateralis

Gastrocnemius
}

contact between origin and insertion is in some way interrupted. The fact that ringed fibres are frequently found in muscles which, physiologically, lack an insertion and/or origin in bone might be an argument in favour of this theory. This mechanism might also explain the fact that ringed fibres so frequently occur in the muscular dystrophies, in which conditions large areas of muscle tissue are replaced by adipose tissue and connective tissue so that the contact between origin and insertion of the remaining muscle fibres is lost.

\section{SUMMARY}

Ringed fibres were found in 31 of 200 muscle biopsy specimens; in 21 of these 31 specimens, sarcoplasmic masses were also found. In 20 post-mortem examinations on patients who had had no neuromuscular disease, ringed fibres and sarcoplasmic masses were more frequently found in muscles without a skeletal insertion and/or origin than in muscles with skeletal attachment.
Ringed fibres were experimentally produced in the quadriceps in guinea-pigs in that the contact between origin and insertion was interrupted by severance of the insertion tendon or the muscle proper.

\section{REFERENCES}

Bacaloglu, C., and Scriban, J. (1916). C. R. Soc. Biol. (Paris), 79, 559. Bataillon, E. (1891). Ann. Univ. Lvon, 2, 1.

Bergstrand, C. G. (1938). Z. mikr.-anat. Forsch., 44, 45

Berthrong, M., and Griffith, P. (1961). J. Path. Bact., 82, 287.

Bethlem, J. (1958). Folia psychiat, neerl., 61, 707.

Bucciante, L., and Luria, S. (1933). Arch. ital. Anat. Embriol., 31, 312. Cooper, S., and Daniel, P. M. (1949). Brain, 72, 1

D'Antona, S. (1926). Policlinico Sez. med., 33, 389.

Doms, H. (1915). Arch. mikr. Anat., 87, 60.

Gamstorp, I. (1956). Acta paediat. (Uppsala), 45, suppl., 108

Goerttler, K. (1935). Verh. dtsch. orthop. Ges., 30, 34

(1950). Z. Anat. EntwGesch., 115, 352.

Goldstein, D. J.. and Zent, D. (1961). S. Afr. J. med. Sci., 26, 84.

Graf, P. (1949). Z. Anat. Entwickl.-Gesch., 114, 399.

Greenfield, J. G., Shy, G. M., Alvord, E. C., and Berg, L. (1957). An Atlas of Muscle Pathology in Neuromuscular Diseases. Livingstone, Edinburgh and London.

Günther, P. G. (1952). Virchows Arch, path. Anat, 322, 214.

Heidenhain, M. (1918). Beitr. path. Anat., 64, 198.

Hoen, A. G. (1898). J. exp. Med., 3, 549.

Malan, E. (1934). Arch. Biol., 45, 355.

Marcus, H. (1925). Z. Anat. Entickl.-Gesch., 76, 578. 
Martinotti, G. (1901). Arch. ital. Biol., 36, 115.

Mori, M. (1953). Arch. histol. jap., 5, 485.

Morris, W. R. (1959). A.M.A. Arch. Path., 68, 438.

Muenzer, E. (1893). Z. klin. Med., 22, 564.

Perry, R. E., Smith, A. G., and Wrenn, R. N. (1956). A.M.A. Arch. Path., 61, 450.

Schaffer, J. (1893). S. B. Akad. Wiss. Wien. math.-nat. Kl. abt. III, $102,7$.

Schütz, H. (1923). Beitr. path. Anat., 71, 451.

Schwarz, M. (1925). Z. Anat. Entwickl.-Gesch., 75, 361.

Scriban, C., and Paulian, D. (1932). Bull. Acad. Méd. (Paris), 107, 853.

Siliotti, I. (1954). Arch. De Vecchi Anat. pat., $20,557$.
Slauck, A. (1921). Z.ges. Neurol. Psychiat., 67, 276.

Steiner, W. R. (1905). J. exp. Med., 6, 407.

Stöhr, P. (1949). Z. Anat. Entwickl.-Gesch., 114, 185.

Thulin, I. (1908). Anat. Anz., 33, 241.

Vecchi, G. (1925). Arch. ital. Biol., 75, 85.

Voss, H. (1932). Z. mikr.-anat. Forsch., 28, 161.

- (1957). Anat. Anz., 104, 345.

Weiss, P., and James, R. (1955). J. exp. Zool., 129, 607.

Wohlfahrt, S., and Wohlfart, G. (1935). Acta med. scand., suppl., 63.

Wohlfart, G. (1937). Acta psychiat. (Kbh.), suppl. 12.

- (1938). Z. mikr.-anat. Forsch., 44, 33.

- (1951). J. Neuropath., 10, 109

\section{The June 1963 Issue}

\section{THE JUNE 1963 ISSUE CONTAINS THE FOLLOWING PAPERS:-}

Diagnosis of Krabbe's infantile leucodystrophy BENGT HAGBERG, PATRICK SOURANDER, and LARS SVENNERHOLM

Organic mercurial encephalopathy W. J. HAY, A. G. RICKARDS, W. H. MCMENEMEY, and J. N. CUMINGS

Encephalopathy in a case of Whipple's disease J. BADENOCH, W. C. D. RICHARDS, and D. R. OPPENHEIMER

Cerebral evoked potentials in patients with dissociated sensory loss A. M. HALLIDAY and G. S. WAKEFIELD

The transfer of ${ }^{35} \mathrm{~S}$-methionine sulphone across the blood-cerebrospinal fluid barrier D. KEMALI, M. K. GAITONDE, and A. J. COPPEN

Extradural cysts of the spinal canal PETER GORTVAI

The radiological appearances of spinal extradural arachnoid cysts H. M. DASTUR

Intramedullary abscess of the spinal cord MICHAEL BETTY and JOHN LORBER
Reversal of Horner's syndrome L. J. CAUST and MARJORIE M. L. PRICHARD

The use of Teflon as a dural substitute and its others क्? neurosurgical applications PAUL TENG and CHRISTOS PAPATHEODOROU

Intracranial oligodendrogliomatosis PHILIP V. BEST

The serum protein changes in giant cell arteritis J. MICHAEL SMALL and KETTY GAVRILESCU

A retrospective controlled study of tranquillizers in long-stay patients A. A. ROBIN

Paired response of motor units during voluntary contraction in Parkinsonism A. DAS GUPTA

The influence of various stimuli upon Parkinsonian tremor and rigidity JANUSZ SUBCZYNSKI, KEIZO MATSUMOTO, TUNG HUI LIN, and IRVING S. COOPER

Precocious puberty due to a hypothalamic hamartoma in a patient surviving to late middle age LIONEL WOLMAN and G. V. BALMFORTH

Book reviews

Copies are still available and may be obtained from the PUBLISHING MANAGER, BRITISH MEDICAL ASSOCIATION, TAVISTOCK SQUARE, W.C.I., price 18s. 6D. 